\title{
Editorial para o Volume 3(1)
}

\section{Rodolfo Coelho de Souza}

Universidade de São Paulo

rcoelho@usp.br

Editor-chefe de MUSICA THEORICA

Este Volume 3(1) demarca uma etapa na trajetória do periódico Musica Theorica que corresponde ao encerramento do mandato de gestão da primeira diretoria da TeMA, a Associação Brasileira de Teoria e Análise Musical que promove a publicação. Em outubro de 2018 os associados da entidade elegeram uma nova diretoria, na qual fui encarregado de ocupar a presidência e com isso encerrar minha atribuição de Editor-chefe que ocupei na primeira gestão.

É com muito orgulho que encerro esta etapa como editor de Musica Theorica oferecendo aos leitores este volume que corresponde a contribuições preparadas e submetidas ao longo dos meses de janeiro a julho de 2018. Este volume tem um título: Teoria e Composição. Porque os artigos publicados atenderam a uma chamada que desafiava os pesquisadores a escrever sobre as relações que pesquisavam entre as bases teóricas da ciência musical e sua prática como compositores.

A variedade das respostas oferecidas a essa provocação foi surpreendente. De fato, apenas dois artigos deste volume abordaram o problema frontalmente. Refiro-me, primeiramente, ao trabalho que aparece como número 8 neste volume, escrito por Achille Picchi, professor da UNESP, reconhecido compositor, analista musical, musicólogo e estupendo pianista - apenas para mencionar algumas de suas competências mais celebradas. Picchi reflete sobre a relação entre o substrato teórico que suporta o exercício da composição, através de dois conceitos que, - propõe ele -, fariam a mediação entre o plano da teoria e o plano da prática: o insight e a expertise. O texto conclui com uma instigante reflexão sobre o famoso ensaio A Filosofia da Composição de Edgar A. Poe em que Picchi coloca em relevo o papel das categorias enunciadas como relevantes para uma compreensão atualizada do ensaio de Poe. 
Outro trabalho que adota uma trajetória semelhante é o de Flávio Santos Pereira, professor da UNB. A perspectiva de Pereira é diferente da de Picchi na medida em que seu objeto de estudo é sua própria produção composicional. Estudos de autoanálise musical foram alvo de críticas num passado recente, mas hoje se reconhece que são essências à evolução da teoria musical. Ao longo dos séculos a teoria musical foi quase que indissociável da prática do compositor, o que nos atesta a história que vai de Zarlino a Schoenberg. Mesmo célebres teóricos, aparentemente especializados, como Schenker e Riemann, também foram compositores, bissextos ou regulares, mas não obstante, praticantes. Em épocas recentes, teóricos e analistas, no âmbito internacional, andaram reclamando para si a exclusividade do território de teoria e análise, mas este volume é prova de que não tiveram sucesso, pelo menos no campo brasileiro. Saliente-se, porém, que a abordagem de Pereira não é nem ingênua, nem confessional. Ele parte do sofisticado conceito de pensamento complexo, proposto por Morin, para reconhecer sua dupla condição de observador e observado, que o leva a reconhecer na prática do compositor a eclosão da dialética entre natureza e cultura, aproximando pensadores diversos desde LéviStrauss aos compositores da linha espectralista francesa, demonstrando assim um amplo domínio da meta-teoria que sustenta sua prática de composição.

Entretanto, os caminhos reflexivos propostos por outros autores deste volume, foram variados e surpreendentes. A pianista e pesquisadora Zélia Chueke, professora da UFPR, faz uma aproximação original, e deliciosa para o leitor, entre os trabalhos do compositor e do artista plástico. Ela nos encanta com sua habilidade para encontrar profundas relações estruturais entre as práticas do pintor Paul Klee e obras musicais de diversos compositores, entre eles Schumann, Debussy, Bach, Mozart, Ravel, tecendo uma trama de relações intertextuais, ou mais precisamente, inter-semióticas, que revelam uma inesperada similaridade entre as estruturas cognitivas na percepção das obras musicais e visuais.

Outro artigo que faz uma aproximação meta-teórica da composição musical é o trabalho de Marcel Castro-Lima, da UNIRIO, em conjunto com Liduino Pitombeira, da UFRJ, participantes de ativo grupo de pesquisa MusMat, abrigado pela pós-graduação da UFRJ. O propósito do artigo é esclarecer o processo composicional de uma obra de Castro-Lima que toma um ponteio de Guarnieri como referência, que empregando a técnica chamada de "modelagem sistêmica" que foi desenvolvida pelos pesquisadores desse grupo. Trata-se, portanto, de um estudo de caso que responde à chamada do volume atestando que a prática da composição pode envolver de fato um grau altamente consciente de formulação teórica.

$\mathrm{O}$ artigo de Miriam Carpinetti parte de outro paradigma. Organista celebrada e também ativa compositora, Carpinetti adota a técnica do alter-ego, num ponto de vista diametralmente oposto ao de Castro-Lima, para falar de seu 
pensamento composicional. Seu artigo trata-se de um estudo de caso em que ela empreende uma decifração da obra de Messiaen a partir do conceito de desleitura. Ou seja, ela mostra que um compositor nunca começa do nada, mas sim do estímulo de outras obras e que sua composição é sempre, em última instância, uma reescrita da obra de um predecessor. Subliminarmente, devemos entender que esse é o método adotado por Carpinetti em sua própria obra e que Messiaen é sua referência absoluta. Se esta perspectiva pode parecer secundária na leitura deste artigo, certamente é primordial sua primorosa análise dos fundamentos teóricos da obra de Messiaen, demonstrando assim, por um estudo de caso, as profundas relações que uma teoria composicional pode ter na escrita musical.

Outro artigo que envereda por metodologia semelhante é o de Antonio Celso Ribeiro, professor da Universidade Federal do Espírito Santo, que analisa uma obra de Oilliam Lanna. Ribeiro entende que essa peça de Lanna não somente se inspira num poema de Charles Baudelaire, mas de fato realiza o que Haroldo de Campos chamaria de uma trans-criação da poesia do grande poeta simbolista francês. Ribeiro empreende uma detalhada análise da música de Lanna para demonstrar como ela mapeia criativamente o poema de Baudelaire. Ribeiro valoriza sobretudo as diversas acepções do conceito de silêncio, tanto como fenômeno perceptivo, como estrutural, para revelar o paralelismo entre as obras.

Fiquei muito honrado com uma submissão para nosso periódico de eminentes colegas da academia lusitana, atestando mais uma vez a vocação de Musica Theorica para uma inserção internacional. Refiro-me ao artigo de Ana Cristina Bernardo, da Escola de Música do Conservatório Nacional, e de Eduardo Lopes, professor da Universidade de Évora, que abre o volume. Eles se debruçam sobre uma composição de Eurico Carrapatoso para quarteto de cordas com piano. Os autores partem de uma reflexão teórica sobre o conceito de metáfora para elaborar em detalhes a relação estrutural entre obras referências da cultura popular e a obra instrumental de Carrapatoso demonstrando como elas inspiraram os níveis estruturais e significantes da composição. Essa análise vai além das preocupações formais, não obstante o reconhecimento de sua hábil elaboração, para salientar os aspectos expressivos que podem ser enfatizados na interpretação, estabelecendo assim uma ponte de validação da performance através da análise musical. Este era um aspecto complementar do problema da relação entre teoria e composição que carecia mesmo ser abordado e enfatizado neste volume.

O artigo de Ricardo Mazzini Bordini, da Universidade Federal do Maranhão, adota um ponto de vista abstrato, mais puramente teórico do que os outros artigos do volume. Trata-se de um estudo muito complexo do espaço atonal expandido de encadeamentos para tricordes. O pressuposto do artigo é que essa teoria sirva de modelo auxiliar para a geração de material précomposicional. Em outras palavras, o ponto de vista implícito do autor é que 
composição não precisa ser uma mera prática, mas pode envolver aspectos teóricos altamente complexos que devem ser desenvolvidos a priori. Além desse mérito que justifica a inclusão do artigo nesta chamada, o trabalho traz uma contribuição valiosa e original para a teoria dos conjuntos, que poderia figurar em qualquer periódico de excelência do mundo, reforçando a vocação de Musica Theorica para abrigar a produção brasileira de excelência na área de teoria musical pura.

As duas derradeiras contribuições para este número ampliam exemplarmente um campo de estudos que tem se revelado, neste periódico, uma importante área de renovação nas aplicações da teoria musical. São dois artigos que envolvem complexos problemas de aplicação da tecnologia musical. O primeiro deles de Ivan Eiji Simurra, da Universidade Federal do ABC, empreende uma análise musical da obra Reflexões de Jônatas Manzolli, importante pesquisador e compositor, professor da UNICAMP. Trata-se de uma empreitada analítica que usa como ferramenta a tecnologia dos descritores computacionais das ondas acústicas. Esse modelo ultrapassa o modelo de análise da partitura a partir das notas, que são reduções simbólicas do signo musical, ao usar programas de computador para analisar a constituição espectro-morfológica do som gravado de uma execução da obra, para dela extrair avaliações que seguem uma modelagem conceitual original do discurso musical.

Finalmente, o derradeiro artigo, aliás o terceiro deste volume, foi escrito por Leandro Gumboski e Ana Leticia Crozetta Zomer que participam de um grupo de pesquisa da USP liderado por Adriana Lopes da Cunha Moreira. O objeto da análise é a obra eletroacústica All Round Me de Russell Pinkston, composta como música funcional de balé, mas lançada posteriormente em CD. Os atores empreendem uma exemplar análise de composição eletroacústica, usando paradigmas analíticos clássicos da eletroacústica, como as teorias espctro-morfológicas de Dennis Smalley e Michel Chion, para desenvolver uma hipótese de narratividade implícita sugerida pelo título da obra e os comentários do compositor que constam do encarte do CD. Convido os leitores do volume a prestarem atenção ao link que consta da nota de rodapé no 7 do artigo que remete a uma postagem no youtube que traz a música de Pinkston sincronizada a uma cativante partitura gráfica elaborada pelos autores do artigo para servir de base para o trabalho analítico que desenvolveram.

Como afirmei acima, com a publicação deste volume encerro minha contribuição à TeMA como primeiro Editor-chefe do periódico Musica Theorica. Gostaria de aproveitar a oportunidade para prestar contas do trabalho empreendido. Gostaria de aproveitar a oportunidade de agradecer a precisosa 
colaboração dos dois editores assistentes que me ajudaram durante este mandato: Carlos de Lemos Almada e Norton Eloy Dudeque, o qual assume a direção da editoria da TeMA a partir de agora.

Em quatro anos de atividade como membro da diretoria, conseguimos, num trabalho de equipe muito engrenado, montar inicialmente a estrutura necessária para a existência do periódico. Faço especial menção à dedicação de Ilza Nogueira, nossa exemplar presidente, que superou todos os muitos obstáculos administrativos para viabilizar a existência de Musica Theorica em tempo recorde. Com isso conseguimos já no primeiro semestre de 2016 colocar no ar a revista online, convocar a primeira chamada de trabalhar e publicar o primeiro volume da revista.

No total foram 5 volumes sob minha editoria: os 1(1) e 1(2) de 2016, os 2(1) e 2(2) de 2017, e este 3(1) de 2018. Deixo para meu sucessor já feita a chamada e praticamente completada a submissão para o volume 3(2) de 2018 que deve ir ao ar em breve.

Nestes 5 volumes foram publicados 47 artigos. Inicialmente almejávamos uma meta de 9 artigos por volume, mas devido à demanda e às novas diretrizes das agências governamentais, especialmente o Scielo, aumentamos essa expectativa para 10 artigos por volume, com periodicidade de 2 volumes por ano, números que temos conseguindo manter.

Especialmente digno de destaque é o fato que $43 \%$ dos artigos publicados foram escritos em línguas de maior alcance internacional que o nosso português, $36 \%$ em inglês e $7 \%$ em francês. É um número que atesta o alcance internacional do periódico desde seu lançamento.

Esse alcance internacional também pode ser medido pelas contribuições de artigos de pesquisadores de diversos países. Os Estados Unidos da América contribuíram com 5 artigos de pesquisadores da Temple University, University de Missouri-Kansas, Eastman School of Music, University of Texas at Austin e Indiana University. A Irlanda colaborou com 1 artigo de professor da Maynooth University. A França com 1 artigo de pesquisadores da Sorbonne [ou 2 artigos se considerarmos a dupla vinculação de uma pesquisadora brasileira que publica neste volume 3(1)]. E finalmente Portugal com 1 artigo. Some-se a isso os outros artigos de pesquisadores internacionais radicados no Brasil e de brasileiros escrevendo em língua estrangeira e teremos o quadro completo da significativa internacionalização do periódico desde sua concepção.

Além do quadro de internacionalização gostaria de enfatizar ampla abrangência nacional do periódico. Como diz a expressão corrente, somos um país de dimensões continentais, de modo que conseguir que a revista atraia contribuições de pesquisadores espalhados por todo o território nacional não é tarefa de pouca ambição. Publicamos artigos originados em 13 dos 27 estados da Federação (por ordem alfabética, Acre, Brasília, Espírito Santo, Maranhão, Mato 
Grosso do Sul, Minas Gerais, Paraíba, Paraná, Rio de Janeiro, Rio Grande do Sul, Roraima, Santa Catarina, São Paulo).

Os pesquisadores que publicaram nos 5 primeiros volumes de $\mathrm{Musica}$ Theorica estão ligados 20 instituições brasileira de ensino e pesquisa, a saber:

- Estaduais de São Paulo: Usp, Unicamp, Unesp e Emesp

- Estaduais do Paraná: Unespar e Londrina

- Estadual de Santa Catarina: Udesc

- Universidades e Institutos Federais: Federal do Acre, Universidade de Brasília, Federal do Espírito Santo, Federal do Maranhão, Federal do Mato Grosso do Sul, Federal do Minas Gerais, Federal do Paraíba, Federal do Paraná, Federal do Rio de Janeiro, e Federal do Estado do Rio de Janeiro, Federal do Rio Grande do Sul, Federal de Roraima, e Instituto Federal de São Paulo

Creio que esse levantamento demonstra o significativo alcance nacional e internacional já obtido pela TeMA e pela revista MUSICA THEORICA em seus três primeiros anos de funcionamento, prenunciando seu auspicioso futuro. 